\title{
Conjugated microporous polymers for near-infrared photothermal control of shape change
}

\author{
Jialong $\mathrm{Wu}^{1}$, Yongwei $\mathrm{Wu}^{1}$, Zepeng $\mathrm{He}^{2}$, Zihua $\mathrm{Li}^{1}$, Huahua Huang ${ }^{1 *}$, Yongming $\mathrm{Chen}^{1}$ and \\ Guodong Liang ${ }^{1 *}$
}

\begin{abstract}
Herein, a facile and highly efficient synthetic method to prepare organic photothermal materials with high photo-stability and outstanding photothermal performance is reported. Through direct polymerization of commercial aromatic monomers in the presence of anhydrous aluminium chloride and dichloromethane, four kinds of conjugated microporous polymers (CMPs) were obtained. Detailed structural analysis confirmed that the resultant CMPs possessed abundant micropores with an extended $\pi$-conjugated skeleton. Under near-infrared (NIR) light irradiation $(808 \mathrm{~nm}$, $1.0 \mathrm{~W} \mathrm{~cm}^{-2}$ ), all the CMPs showed fast heating-up behavior with their maximum temperatures higher than $150^{\circ} \mathrm{C}$. Moreover, the efficiency of photothermal conversion $(\eta)$ of the CMPs was found to increase linearly with the increase in the number of conjugated benzene rings within the monomer. Poly-TPE from tetraphenylethylene (TPE) and Poly-TP from o-terphenyl (TP) showed high $\eta$ values of over $47 \%$. Poly-TPE was additionally used as a photothermal filler to remotely and spatially control the shape recovery of thermal-sensitive shape memory polymers (SMPs), while its introduction (1 wt\%) had little influence on the thermal and mechanical properties of the polymer matrixes. Owing to their excellent NIR photothermal performance as well as a one-step synthetic preparation, these CMPs may be promising photothermal materials for practical applications.
\end{abstract}

Keywords: conjugated microporous polymer, photothermal conversion, near-infrared, actuator

\section{INTRODUCTION}

In the recent decade, microporous organic polymers (MOPs), which are microporous, covalent and purely organic materials, have attracted great interest in the fields of gas separation, energy storage and catalysis [1-4].
MOPs possess the advantages of having a high surface area with a pore diameter below $2 \mathrm{~nm}$, high chemical and thermal stability, and chemical functionalization, and thus have the prospect to complement typical microporous materials such as activated carbons, zeolites, and the extensively studied metal-organic frameworks [5]. Currently, various MOPs with different structures such as hypercrosslinked polymers, covalent triazine frameworks, conjugated microporous polymers (CMPs) and polymers with intrinsic microporosity have been reported [6-8]. In particular, CMPs with an extended $\pi$-conjugated structure are a highly attractive class of MOPs $[9,10]$. Due to their unique conjugated and porous structure, some CMPs exhibit outstanding luminescence [11] and supercapacitive energy storage properties [12], and thus they have potential applications in optoelectronics and semiconducting fields. Nevertheless, the photothermal conversion behavior of the CMPs has been seldom studied [13]. The extended $\pi$-conjugated structure of CMPs may endow them with the ability to convert electromagnetic radiation energy into thermal energy, and thus CMPs may be a new type of photothermal materials.

The research on photothermal materials that can absorb and convert sunlight into heat energy through nonradiative exothermic reaction, is of great importance in terms of environmental protection and energy exploitation [14-16]. Near-infrared (NIR) light can penetrate through materials, and thus NIR photothermal materials are promising candidates for photothermal use in many fields such as medicine, robotics and intelligent systems [17-20]. In comparison with inorganic materials, e.g., carbon or gold-based materials [21-23], organic NIR photothermal materials possess good biocompatibility and functionalization, as well as superior disperse beha-

${ }^{1}$ School of Materials Science and Engineering, Key Laboratory for Polymeric Composite and Functional Materials of Ministry of Education, Sun Yatsen University, Guangzhou 510275, China

${ }^{2}$ School of Chemistry, Sun Yat-sen University, Guangzhou 510275, China

* Corresponding authors (emails: huanghh27@mail.sysu.edu.cn (Huang H); lgdong@mail.sysu.edu.cn (Liang G)) 
vior when blended into polymeric matrixes [24-27]. Therefore, increasing attention has been focused on the development of organic photothermal materials, especially conjugated polymers [28-31]. Besides the common polyaniline [32] and polypyrrole [33], some conjugated polymers have emerged as novel photothermal materials [34]. For example, Cao et al. [35] synthesized a narrowbandgap conjugated polymer containing thiophene and bithiophene which could absorb NIR-II light $(1000-1700 \mathrm{~nm})$ that can penetrate tissue deeper than NIR-I light, and convert it into thermal energy. Recently, Chen et al. [36] reported a relatively facile synthetic method involving click condensation reaction to prepare conjugated polymers with good NIR photothermal properties. Nevertheless, their monomers were commercially unavailable and the product yield was not high. Generally, conjugated polymers with photothermal effect suffer problems related to several tedious synthetic steps involving low yield, making them hardly considered for practical applications.

Herein, we report a one-step, high-yielding synthetic method to obtain organic photothermal materials with good NIR photothermal properties using commercially available aromatic monomers. As shown in Scheme 1, four kinds of aromatic monomers including benzene (B), biphenyl (BP), $o$-terphenyl (TP) and tetraphenylethylene (TPE) were polymerized in the presence of anhydrous aluminium chloride $\left(\mathrm{AlCl}_{3}\right)$ and dichloromethane $\left(\mathrm{CH}_{2} \mathrm{Cl}_{2}\right)$ to obtain the corresponding polymers named Poly-B, Poly-BP, Poly-TP and Poly-TPE, respectively. Recently, the syntheses of Poly-B and Poly-BP using the same method, and their porous structure and gas storage were reported $[37,38]$. However, their photothermal performance was not studied. We focus on investigating the relation between the efficiency of photothermal conversion and molecular structure of the CMPs. Also, the CMPs will be used as NIR photothermal actuators to control the shape recovery of shape memory polymers (SMPs).

\section{EXPERIMENTAL SECTION}

\section{Materials}

Anhydrous $\mathrm{AlCl}_{3}, \mathrm{~B}, \mathrm{BP}, \mathrm{TP}$ and TPE were purchased from Shanghai Macklin Biochemical Corporation Ltd. $\varepsilon$ caprolactone (CL, 99\%), diphenyl phosphate (DPP, 99\%) were purchased from Aladdin. Ethylene glycol (EG, AR) was from Guangzhou Chemical Reagent Factory. Dibutyltin dilaurate (DBTL, 95\%) and hexamethylene diisocyanate (HDI, 99\%) were offered by Sigma. Ethanol was purchased from the National Medicines Corporation Ltd.

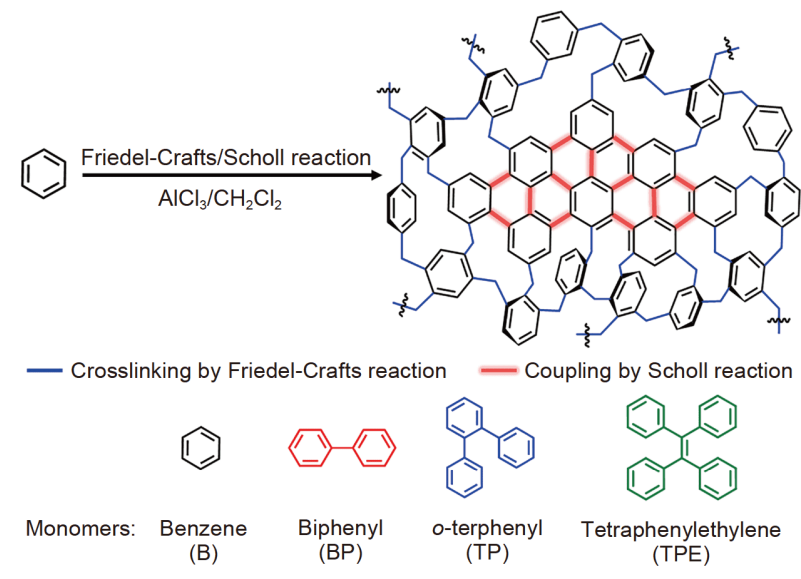

Scheme 1 Schematic illustration of the synthesis of CMPs by using commercial aromatic monomers in the presence of $\mathrm{AlCl}_{3}$ and $\mathrm{CH}_{2} \mathrm{Cl}_{2}$.

Anhydrous $\mathrm{CH}_{2} \mathrm{Cl}_{2}$ and toluene were dried with $\mathrm{CaH}_{2}$ and distilled under an $\mathrm{N}_{2}$ atmosphere. $\mathrm{CL}$ was dried with $\mathrm{CaH}_{2}$ and collected through reduced pressure distillation.

\section{Syntheses}

\section{Preparation of CMPs}

To a solution of B, BP, TP or TPE monomer $(5 \mathrm{mmol})$ in anhydrous $\mathrm{CH}_{2} \mathrm{Cl}_{2}(100 \mathrm{~mL})$, anhydrous $\mathrm{AlCl}_{3}(50 \mathrm{mmol}$, $6.67 \mathrm{~g}$ ) was added. The mixture was stirred at $80^{\circ} \mathrm{C}$ under an $\mathrm{N}_{2}$ atmosphere for $24 \mathrm{~h}$. The reaction was terminated with ethanol and then the resulting precipitate was filtered and washed with $\mathrm{HCl}-\mathrm{H}_{2} \mathrm{O}(20 \mathrm{~mL}, v / v=1: 1)$, deionized water and ethanol in succession. Further purification was applied by a Soxhlet extractor with $\mathrm{CH}_{2} \mathrm{Cl}_{2}$ for $24 \mathrm{~h}$ to remove any residual monomer. The final product was dried in a vacuum oven at $60^{\circ} \mathrm{C}$ for $12 \mathrm{~h}$ and a dark powder was obtained. Yields: Poly-B, $0.51 \mathrm{~g}$ $(130 \%),{ }^{13} \mathrm{C}$ cross-polarization/magic-angle spinning nuclear magnetic resonance (CP/MAS NMR) $\delta$ (ppm): 136.0, 129.8, 66.0, 40.4, 20.3; Poly-BP, $0.96 \mathrm{~g}(125 \%),{ }^{13} \mathrm{C}$ CP/MAS NMR $\delta$ (ppm): 140.9, 131.9, 67.4, 35.5, 20.3; Poly-TP, $1.57 \mathrm{~g}(136 \%),{ }^{13} \mathrm{C}$ CP/MAS NMR $\delta(\mathrm{ppm})$ : $140.2,131.2,66.0,36.9,18.2$; Poly-TPE, $2.22 \mathrm{~g}(134 \%),{ }^{13} \mathrm{C}$ CP/MAS NMR $\delta$ (ppm): 139.5, 130.5, 68.1, 39.7, 19.6.

Synthesis of poly(E-caprolactone) diols (PCL)

CL $(20.0 \mathrm{~g}, 175.2 \mathrm{mmol}), 0.2722 \mathrm{~g}$ of EG $(4.4 \mathrm{mmol})$ and $2.1942 \mathrm{~g}$ of DPP $(8.8 \mathrm{mmol})$ were added into $175 \mathrm{~mL}$ of dry toluene and stirred at room temperature (r.t.) in a glove box of $\mathrm{N}_{2}$ atmosphere for $16 \mathrm{~h}$. The polymerization was terminated by adding benzoic acid and the crude powder was precipitated in methanol three times. The 
product was dried under vacuum for $12 \mathrm{~h}$. Yield: $98 \% . M_{\mathrm{n}}$ of PCL calculated by ${ }^{1} \mathrm{H}$ NMR: $4600 \mathrm{~g} \mathrm{~mol}^{-1}$.

\section{Synthesis of shape memory polyurethanes (SMPUs)}

PCL $(5.0 \mathrm{~g})$, HDI $(0.4029 \mathrm{~g})$ and DBTL (5 drops) were stirred at $80^{\circ} \mathrm{C}$ in a glove box of $\mathrm{N}_{2}$ atmosphere for $15 \mathrm{~min}$. Then EG $(0.1029 \mathrm{~g})$ and dry $\mathrm{N}, \mathrm{N}$-dimethylformamide (DMF, $10 \mathrm{~mL}$ ) were added into the reaction mixture. The reaction was completed after $5 \mathrm{~h}$. The product was dried at $80^{\circ} \mathrm{C}$ under vacuum.

\section{Preparation of SMPU/CMP composite films}

The films were created by using an evaporation method with DMF as the solvent. CMP powder was dispersed in $2 \mathrm{~mL}$ of DMF and the SMPU was dissolved in $3 \mathrm{~mL}$ of DMF, respectively. Then they were mixed together and poured into a Teflon mold. The mixture was dried at $60^{\circ} \mathrm{C}$ in an oven for $12 \mathrm{~h}$, and then further dried at $80^{\circ} \mathrm{C}$ in a vacuum oven. Finally, a SMPU/CMP film was obtained.

\section{Characterizations}

\section{Chemical structure}

Solid-state ${ }^{13} \mathrm{C} C \mathrm{CP} / \mathrm{MAS}$ NMR spectra were measured on a $400 \mathrm{MHz}$ Bruker superconducting Fourier transform nuclear magnetic spectrometer with a spinning frequency of $20 \mathrm{kHz}$ and a 2.5 -mm MAS probe. ${ }^{1} \mathrm{H}$ NMR spectra of PCL and SMPUs were performed on a Bruker AVANCE III $400 \mathrm{MHz}$ instrument at r.t. with $\mathrm{CDCl}_{3}$ as the solvent. Fourier-transform infrared (FT-IR) spectra were measured by using a Nicolet/Nexus 670 FI-IR spectrophotometer. The samples were firstly mixed with $\mathrm{KBr}$ and then pressed into transparent wafers. Raman spectra were collected on a laser micro-Raman spectrometer (Thermo Fisher DXR2xi) with a laser source of $532 \mathrm{~nm}$. X-ray photoelectron spectroscopy (XPS) spectra of the CMPs were recorded on an ESCALAB 250 surface analysis system. Wide-angle X-ray diffraction (WXRD) patterns were tested by using the XRD diffractometer (D-MAX 2200 VPC) with Ni-filtered $\mathrm{Cu} \mathrm{Ka}$ radiation. The diffractometer was scanned in the $2 \theta$ range from $2^{\circ}$ to $80^{\circ}$ at a rate of $1.5^{\circ} \mathrm{min}^{-1}$. A field-emission scanning electron microscope (SEM, Hitachi) was used to observe the morphologies of CMPs and SMPU/CMP composite films. Before observation, the composite films were fractured in liquid nitrogen.

\section{Thermal property}

Thermogravimetric analysis (TGA) was performed using a Perkinelmer PE Pyris1 TGA in a temperature range from 50 to $800^{\circ} \mathrm{C}$ at a heating rate of $10^{\circ} \mathrm{C} \mathrm{min}{ }^{-1}$ under an $\mathrm{N}_{2}$ atmosphere. Samples were degassed at $100^{\circ} \mathrm{C}$ under an $\mathrm{N}_{2}$ flow for 5 min before testing. The melting temperature $\left(T_{\mathrm{m}}\right)$ and crystalline properties of SMPU and its composites were measured using a PerkinElmer DSC-4000, under an $\mathrm{N}_{2}$ atmosphere with a $10^{\circ} \mathrm{C} \mathrm{min}{ }^{-1}$ heating (or cooling) rate from -60 to $100^{\circ} \mathrm{C}$ (or reverse). The storage modulus was tested on DMA (TA, Q800). The testing temperature was from -80 to $100^{\circ} \mathrm{C}$ with a $5^{\circ} \mathrm{C} \mathrm{min}^{-1}$ heating rate and a frequency of $1 \mathrm{~Hz}$.

\section{Microporous structure}

The surface area and pore size parameters were characterized by using a Micromeritics ASAP2460 surface area and porosity analyzer. Before analysis, the samples were degassed at $110^{\circ} \mathrm{C}$ under $10^{-5}$ bar vacuum for $5 \mathrm{~h}$.

\section{Light absorption and emission}

The data of UV-Vis spectroscopy was collected by using a Hitachi U3500 instrument at r.t. NIR emission spectrum was recorded by using an Edinburgh FLS980 fluorescence spectrometer.

\section{Photothermal effect}

The photothermal effect characterization was performed under a LASERWAVE $808 \mathrm{~nm}$ laser resource, and a FLUKE thermal imager was utilized as a recorder. Each polymeric powder was spread on a quartz slide to form a thin round layer of about $8 \mathrm{mg} \mathrm{cm}^{-2}$, and the measurement was performed at a distance of $8 \mathrm{~cm}$ from the light guide.

\section{NIR sensitive SME}

A rectangular shape was cut from the SMPU/CMP (5 wt\%) film to perform the local recovery. The sample was deformed to a " $U$ " shape in an oven at $60^{\circ} \mathrm{C}$. Then the temporary shape was fixed in an ice/water mixture. Next, part of the "U" shape was put under the $808 \mathrm{~nm}$ NIR light of $0.6 \mathrm{~W} \mathrm{~cm}^{-2}$ light intensity.

\section{RESULTS AND DISCUSSION}

\section{Synthesis and characterization of CMPs}

In order to study the influence of the conjugated structures of CMPs on the efficiency of NIR photothermal conversion, four aromatic monomers were chosen to prepare the corresponding polymers as shown in Scheme 1. The polymerization was performed using $\mathrm{AlCl}_{3}$ as the catalyst and $\mathrm{CH}_{2} \mathrm{Cl}_{2}$ as the solvent at $80^{\circ} \mathrm{C}$. After polymerization for $24 \mathrm{~h}$, polymeric powders of dark color and micro-size particles (Fig. S1a) were obtained with 
extremely high yields of over $120 \%$. The polymers were insoluble in common organic solvents such as $\mathrm{CH}_{2} \mathrm{Cl}_{2}$, tetrahydrofuran, DMF and toluene. In addition, through TGA (Fig. S2), it was found that the polymers have high thermal stability with a decomposition temperature of over $350^{\circ} \mathrm{C}$ under an $\mathrm{N}_{2}$ atmosphere. The chemical structures of the resultant CMPs were characterized by using FT-IR and ${ }^{13} \mathrm{C} C \mathrm{CP} / \mathrm{MAS}$ NMR. Fig. 1a presents the FT-IR spectra of the four polymers. The absorbance bands ascribed to the $\mathrm{C}-\mathrm{H}$ stretching vibration of the alkyl chain are observed in the region of $2750-3000 \mathrm{~cm}^{-1}$ for all the polymers, indicating that the Friedel-Crafts alkylation reaction occurred during the polymerization process. In the ${ }^{13} \mathrm{C}$ CP/MAS NMR spectra of the polymers (Fig. 1b), the resonance peaks around 130 and $140 \mathrm{ppm}$ are ascribed to non-substituted aromatic carbons and substituted aromatic carbons, respectively. The resonance peaks around 67 and $20 \mathrm{ppm}$ belong to the $\mathrm{CH}_{2}$ and $\mathrm{CH}_{3}$ of $\mathrm{ArCH}_{2} \mathrm{OCH}_{2} \mathrm{CH}_{3}$ units, respectively. The units were introduced when Friedel-Crafts alkylation reaction was quenched by ethanol. The resonances of the $\mathrm{CH}_{2}$ next to two benzene rings were detected in the upfield region of 25-45 ppm, further confirming the existence of the methylene units between the aromatic rings, which is derived from $\mathrm{CH}_{2} \mathrm{Cl}_{2}$ serving as an external cross-linker as previously reported $[39,40]$. Thus, it is reasonable that the yields of the products were discovered to be higher than $120 \%$ when only the amount of monomer was taken into account for the calculation. In addition, it should be noted that the $\mathrm{AlCl}_{3}$ catalyst residue did not exist in the products, which is confirmed by the XPS spectra of the polymers (Fig. S3). Any peak around $70 \mathrm{eV}$ relating to $\mathrm{Al}$ element was not detected.

The structures of the polymers were further studied by
Raman spectrometry and WXRD measurement. As shown in Fig. 2a, besides the appearance of a broad peak at $5^{\circ}-30^{\circ}$ signifying their amorphous nature, a small diffraction peak at $42.5^{\circ}$ is observable in all the WXRD patterns, indicating the existence of an in-plane $\mathrm{sp}^{2}$ domain within the polymers [41.] In the Raman spectra of Fig. $2 b$, the $G$ and $D$ bands belonging to the in-plane $\mathrm{sp}^{2}$ domains also appeared at 1590 and $1371 \mathrm{~cm}^{-1}$, respectively [42]. These results mean that apart from the Friedel-Crafts alkylation reaction, a Scholl coupling reaction to form the aryl-aryl bonds also occurred during the polymerization, which led to the formation of the extended $\pi$-conjugated skeleton among the polymers. Moreover, through calculating the ratios of the peak intensities of the $\mathrm{D}$ and $\mathrm{G}$ bands, the $I_{\mathrm{D}} / I_{\mathrm{G}}$ ratios can be obtained, which are related to the regularity of the conjugated structure [43]. It was found that the $I_{\mathrm{D}} / I_{\mathrm{G}}$ ratio of Poly-TPE $(0.70)$ was the smallest among the synthesized polymers. This indicates that in comparison with the other three polymers, Poly-TPE has a more regular conjugated structure and a larger in-plane $\mathrm{sp}^{2}$ domain, attributed to the TPE monomer possessing four conjugated benzene rings.

In addition, the polymers possess a microporous structure with a narrow pore width less than $2 \mathrm{~nm}$, as measured by the $\mathrm{N}_{2}$ sorption isotherm experiment (Figs S4 and S5). The BET surface area and the pore volume of Poly-TPE are the highest among the synthesized polymers reaching up to $1156 \mathrm{~m}^{2} \mathrm{~g}^{-1}$ and $0.59 \mathrm{~cm}^{3} \mathrm{~g}^{-1}$, respectively (Table $\mathrm{S} 1$ ).

According to the above structural analyses, the resulting polymers have two kinds of crosslinking networks: one is obtained via the Friedel-Crafts alkylation reaction and the other is via the Scholl coupling reaction to form
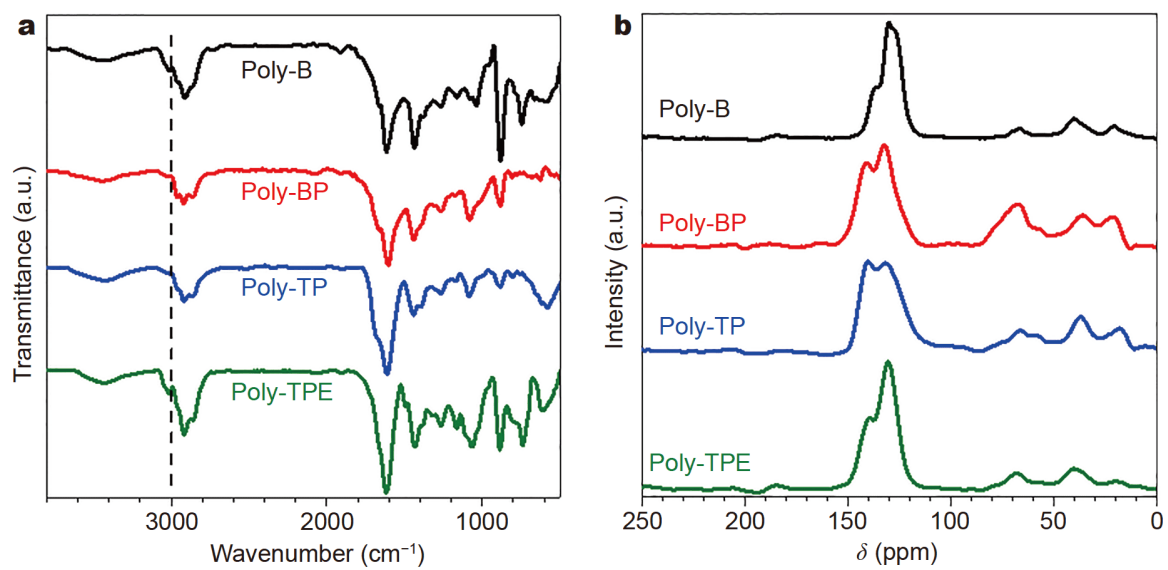

Figure 1 (a) FT-IR spectra and (b) ${ }^{13} \mathrm{C}$ CP/MAS NMR spectra of the CMPs. 
the extended $\pi$-conjugated structure as shown in Scheme 1 . Because of the large $\pi$-conjugated structure, the largest UV absorption peaks for all the polymers appear at $450-600 \mathrm{~nm}$ (Fig. 3a), which is red-shifted by around $200 \mathrm{~nm}$ compared with the peaks of their corresponding monomers (Fig. 3b). All the polymers show a very broad UV absorbance band from 200 to $1200 \mathrm{~nm}$ with their absorbance values being fairly high at around $800 \mathrm{~nm}$ (about 0.8). This indicates that the CMPs have the feature of NIR absorbance.

Additionally, the CMPs showed negligible light emission upon irradiation at $808 \mathrm{~nm}$ (Fig. S6), demonstrating the dominant non-radiative transition reactions of the CMPs. Therefore, the NIR photothermal conversion performances of these CMPs were studied by using NIR light of $808 \mathrm{~nm}$.

\section{Photothermal conversion property of CMPs}

Under irradiation by NIR light of $808 \mathrm{~nm}\left(1.0 \mathrm{~W} \mathrm{~cm}^{-2}\right)$, all the polymers showed a remarkable temperature raise and reached their temperature plateaus within $1 \mathrm{~min}$ as shown in Fig. 4a, indicating their fast heating-up ability. Also, it was found that the maximum temperature of the CMPs presented a closely linear increasing trend with the increase in the number of aromatic rings within the monomers (Fig. S7). The maximum photothermal temperature of $160^{\circ} \mathrm{C}$ for Poly-TPE is obviously higher than that of $152^{\circ} \mathrm{C}$ for Poly-B. This suggests that an increase in the number of conjugated aromatic rings of the monomers favors the formation of large in-plane $\mathrm{sp}^{2}$ domains among the polymers. Moreover, the results of the heat-tocool cyclic tests demonstrate the high photo-stability of the CMPs at high temperatures (Fig. 4b), which is attributed to the high thermal-stability and effective NIR absorbance of materials. Fig. $4 c$ exhibits that there is a linear relation between the photothermal effect of the CMPs and the NIR light intensity from 0.5 to $1.0 \mathrm{~W} \mathrm{~cm}^{-2}$, suggesting the thermal control performance of materials.
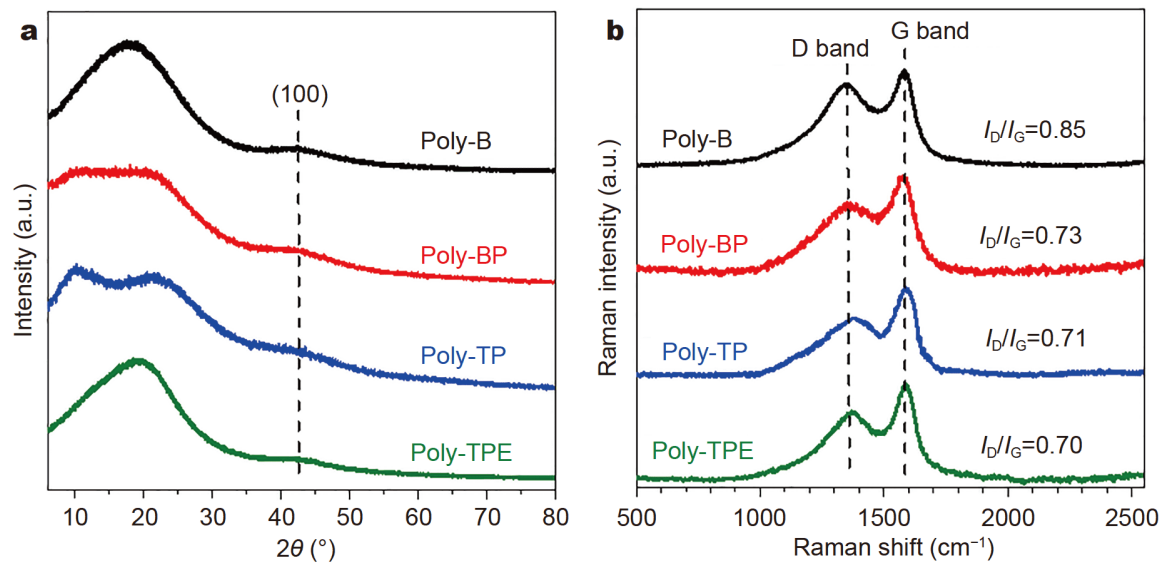

Figure 2 (a) WXRD patterns and (b) Raman spectra of the polymer networks.
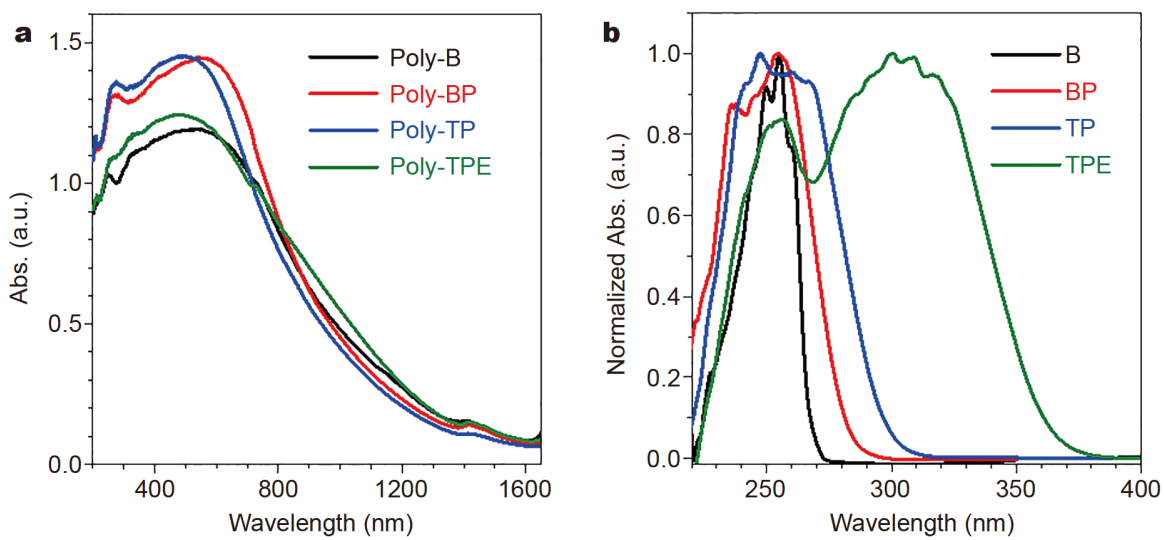

Figure 3 UV-vis spectra of (a) the polymer networks and (b) the monomers. 

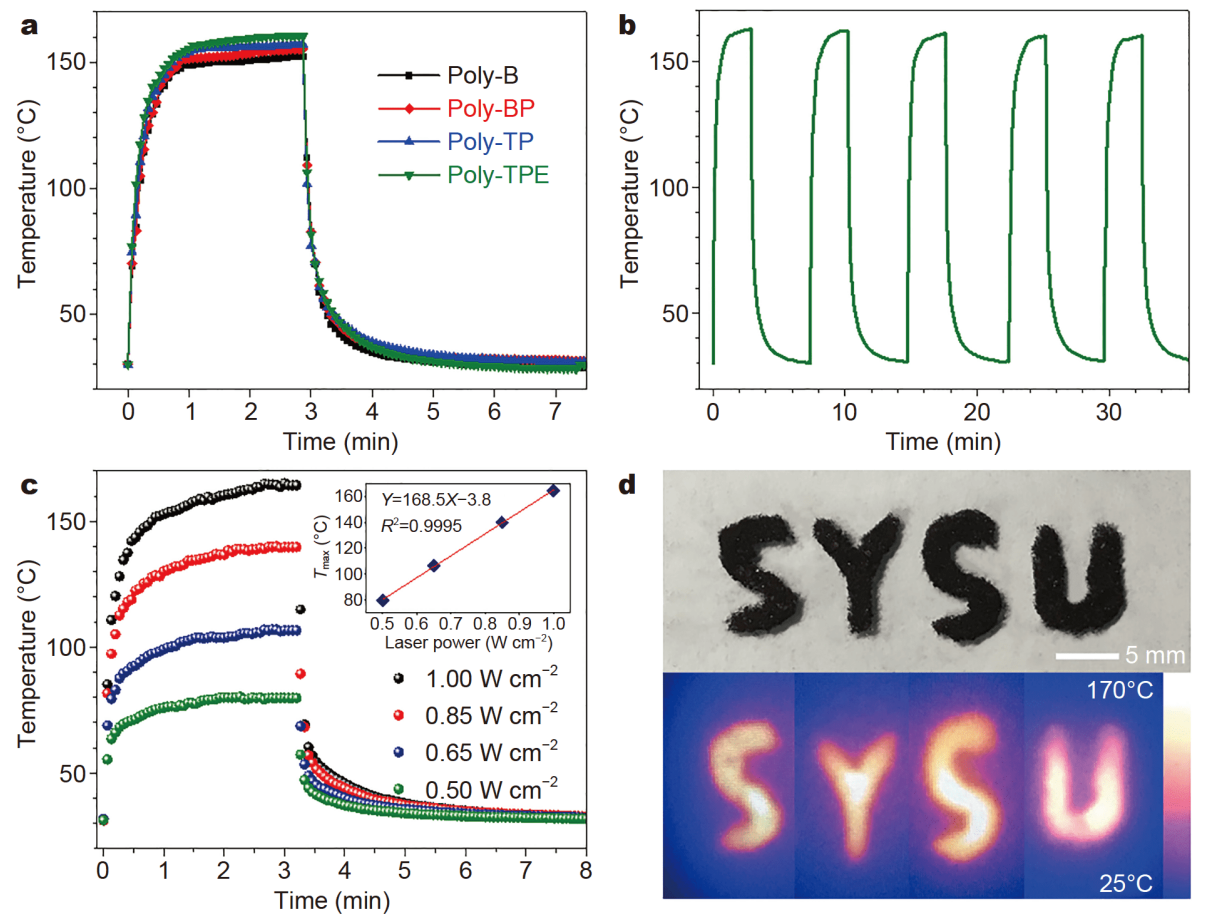

Figure 4 (a) Time-dependent photothermal conversion curves $\left(808 \mathrm{~nm}, 1.0 \mathrm{~W} \mathrm{~cm}^{-2}\right)$ of the polymers. (b) Photothermal cyclic curves of Poly-TPE $\left(808 \mathrm{~nm}, 1.0 \mathrm{~W} \mathrm{~cm}^{-2}\right)$. (c) Temperature rises of Poly-TPE at different NIR laser powers. Inset shows the average maximum temperature $\left(T_{\max }\right)$ as a function of light intensity. (d) IR camera images of Poly-TPE patterned letters SYSU $\left(808 \mathrm{~nm}, 1.0 \mathrm{~W} \mathrm{~cm}^{-2}\right)$.

In addition, the letter patterns "SYSU" were fabricated with Poly-TPE powders and rapidly became imageable (Fig. 4d), under irradiation by NIR light of $808 \mathrm{~nm}$ $\left(1.0 \mathrm{~W} \mathrm{~cm}^{-2}\right)$. It means that the CMPs are of potential use in photothermal imaging and therapy fields. It should also be noted that the monomers did not show NIR photothermal effect (Fig. S8), indicating that the NIR photothermal conversion behavior of the polymers is fully ascribed to their extended $\pi$-conjugated structures.

To calculate the efficiency of the photothermal conversion $(\eta)$, the rate in the temperature decrease of the polymers after removing the light source was measured (Fig. S9). The $\eta$ values of all the polymers were calculated according to Ref. [44] and the details were offered in the Supplementary information. As listed in Table 1, the $\eta$ values of these CMPs follow this order: Poly-TPE $>$ Poly$\mathrm{TP}>$ Poly-BP $>$ Poly-B, which is in accordance with the maximum photothermal temperature result of the CMPs. Moreover, the $\eta$ values of Poly-TPE and Poly-TP are as high as $48.1 \%$ and $47.5 \%$, respectively. These data are comparable to the high $\eta$ values of the reported photothermal polymers, such as selenophene-derived polymer films (40\%), and thiophene-fused benzodifurandionebased oligo( $p$-phenylenevinylene) films (50.5\%) [17,35].
Table 1 Photothermal conversion parameters of the CMPs

\begin{tabular}{ccccc}
\hline Samples & $T_{\max }{ }^{\mathrm{a}}\left({ }^{\circ} \mathrm{C}\right)$ & $\tau_{\mathrm{s}}^{\mathrm{b}}(\mathrm{s})$ & $\mathrm{Abs}^{\mathrm{c}}$ & $\eta^{\mathrm{d}}(\%)$ \\
\hline Poly-B & $152 \pm 1$ & 8.19 & 0.81 & 33.1 \\
Poly-BP & $155 \pm 1$ & 7.56 & 0.85 & 36.3 \\
Poly-TP & $157 \pm 1$ & 6.10 & 0.75 & 47.5 \\
Poly-TPE & $160 \pm 1$ & 5.92 & 0.84 & 48.1 \\
\hline
\end{tabular}

a) Equilibrium temperature under $1.0 \mathrm{~W} \mathrm{~cm}^{-2}$ irradiation; b) system constant time; c) UV absorbance at $808 \mathrm{~nm}$; d) NIR photothermal conversion efficiency.

As mentioned above, there are methylene bridges between the aromatic rings within these CMPs except for the conjugated structure. Nevertheless, Poly-TPE and Poly-TP still showed such high photothermal conversion performance, perhaps ascribed to their microporous structure. It is reported that light trapping of porous polymers could be enhanced and their $\eta$ values could be improved due to the porous structure [45]. These results indicate that our synthesized CMPs have excellent thermal-/photo-stability and high photothermal conversion efficiencies, as well as the feasibility of synthesis from commercially available monomers using a scalable and efficient method, thus enabling them to be considered a 
highly attractive class of photothermal materials for many application fields.

\section{NIR-responsive SMP/CMP composites}

To investigate the potential NIR photothermal application of the CMPs for the control of phase change, CMP powders were introduced into conventional thermoresponsive SMP matrixes to prepare NIR-responsive SMPs. Currently, NIR-responsive SMPs have attracted great interest in application fields (e.g., biomedicine, aerospace and flexible electronics) due to their remote, spatial and real-time control of temporary shapes of SMP materials [46]. However, only a few organic NIR photothermal fillers such as polydopamine and polyaniline have been used to control shape recovery of SMPs [47-49].

Herein, Poly-TPE powder was used as an example to blend into the typical SMPU matrixes, to form SMPU/ CMP composite films. The morphology of the composites was firstly studied by SEM. The SEM micrograph (Fig. S1b) shows the flat-like and no distinct "ball-andsocket" surface topography of cold fractured SMPU/ CMP-1 film (1 wt\%) edges. It indicates that the composite has good compatibility, which is important for the photothermal performance, thermal and mechanical properties of the composite. Under irradiation by NIR light of
$808 \mathrm{~nm}\left(1.0 \mathrm{~W} \mathrm{~cm}^{-2}\right)$, it is clearly observed that the temperature of the SMPU/CMP-3 film (3 wt\%) remarkably increased while the one of the blank film changed little, through using an infrared thermal imager (Fig. 5a). Similar to pure Poly-TPE powder, the composite films showed rapid heating-up behavior and reached the maximum temperature within 1 min (Fig. 5b). Obviously, along with an increase in the content of Poly-TPE powder or the NIR intensity, the composite films showed superior photothermal effect (Fig. 5c). Under $0.6 \mathrm{~W} \mathrm{~cm}^{-2}$ irradiation, the temperature of the SMPU/CMP-1 film (1 wt\%) reached $48.5^{\circ} \mathrm{C}$ within $1 \mathrm{~min}$, and that of the SMPU/CMP-5 (5 wt \%) was over $60^{\circ} \mathrm{C}$ in only $10 \mathrm{~s}$, which are sufficient for the phase transition of SMPU $\left(T_{\mathrm{m}}=\right.$ $45.4^{\circ} \mathrm{C}$ ). A SMPU/CMP-5 strip was firstly programmed into a $U$ shape upon heating. Then as the NIR light was focused on the designated places (indicated by purple rings), the $U$ shape unfolded step by step into the original shape as shown in Fig. 5d (Movie S1). However, the temporary L shape of pure SMPU strip still kept the shape and cannot recover to the original straight one under NIR light (Movie S2). These results indicate that the shape recovery of SMPU/CMP films can be remotely and spatially controlled through NIR irradiation.

Additionally, the introduction of Poly-TPE has negli- a
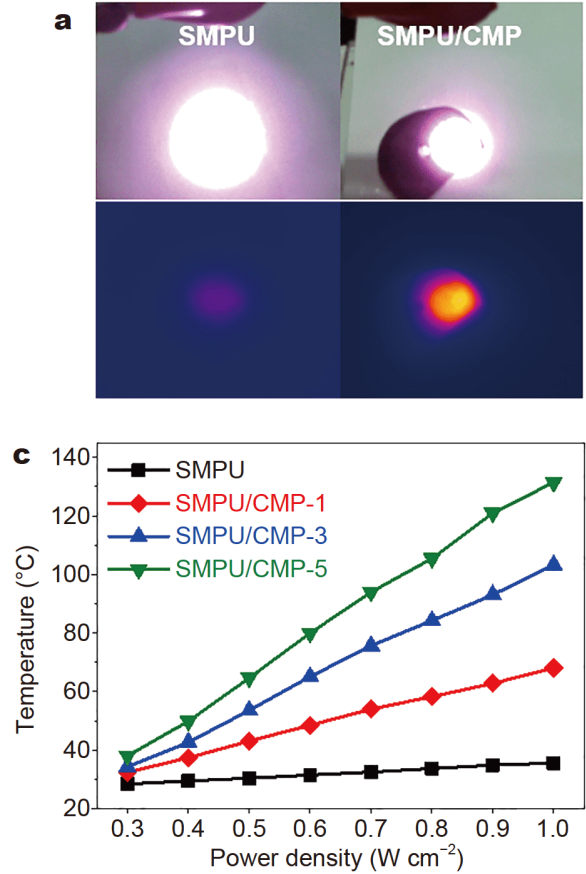
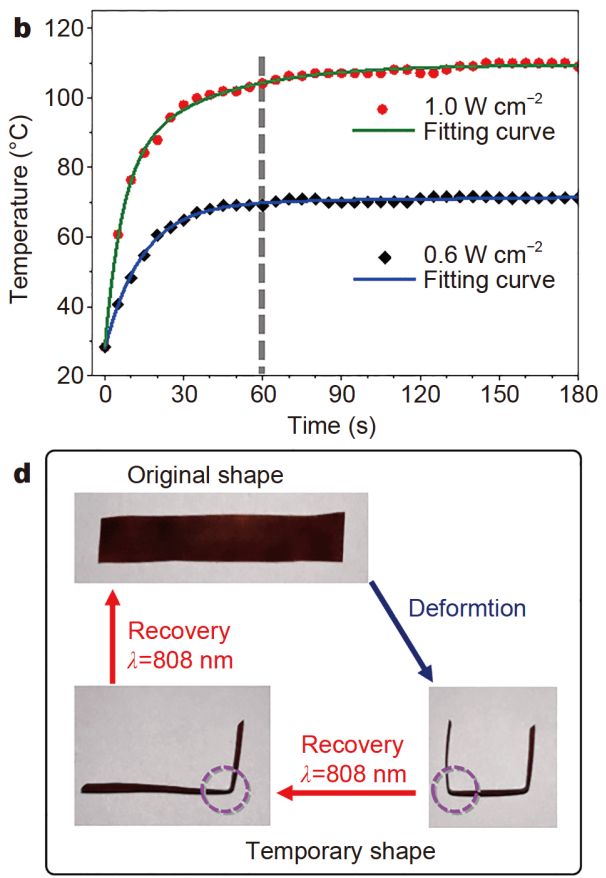

Figure 5 (a) Optical and IR thermal images of SMPU and SMPU/CMP-3 films under $808 \mathrm{~nm}$ laser irradiation. (b) Local temperature as a function of irradiation time for SMPU/CMP-3 film (laser irradiation: $808 \mathrm{~nm}$ ). (c) The temperature as a function of light intensity for SMPU and composite films with different CMP contents. (d) Spatial control of the shape recovery of a SMPU/CMP-5 strip. 
Table 2 Thermal properties of SMPU film and SMPU/CMP composites films

\begin{tabular}{cccc}
\hline Samples & $T_{\mathrm{m}}{ }^{\mathrm{a}}\left({ }^{\circ} \mathrm{C}\right)$ & $\Delta H_{m}{ }^{\mathrm{a}}\left(\mathrm{J} \mathrm{g}^{-1}\right)$ & $X_{\mathrm{c}}^{\mathrm{b}}(\%)$ \\
\hline SMPU & 44.6 & 45.1 & 44.7 \\
SMPU/CMP-1 & 45.4 & 46.8 & 46.9 \\
SMPU/CMP-3 & 45.2 & 43.8 & 44.8 \\
SMPU/CMP-5 & 45.5 & 40.6 & 42.2 \\
\hline
\end{tabular}

a) Melting point and melting enthalpy of PCL segment; b) crystallinity of PCL segment was obtained by dividing the measured heat of fusion by the theoretical data $\left(135 \mathrm{~J} \mathrm{~g}^{-1}\right)$ for pure PCL.

gible influence on the thermal properties of SMPUs even if the particle content was as high as $5 \mathrm{wt} \%$, confirmed by DSC, TGA and dynamic thermomechanical analysis tests (Figs S10-S12). As shown in Table 2, the melting temperatures $\left(T_{\mathrm{m}}\right)$ of the composites are almost the same as that of the blank SMPU, and the composites still possess high crystalline ability of PCL segment. In addition, the SMPU/CMP-1 (1 wt\%) film had comparable mechanical properties including tensile strength and tensile modulus to the blank SMPU film (Fig. S13).

\section{CONCLUSIONS}

In conclusion, a kind of organic photothermal materials including Poly-TP and Poly-TPE with high efficiency of photothermal conversion is reported. To the best of our knowledge, research into the photothermal properties of CMPs remains scarce. We found that the resulting CMPs not only possess microporous structure but also have large in-plane $\mathrm{sp}^{2}$ domains within the polymers. Owing to the extended $\pi$-conjugated structure, all the resulting CMPs can efficiently absorb NIR light and convert it to heat energy. More importantly, comparative studies reveal the significance of the conjugated structure of the monomers on the photothermal performance of the polymers. Poly-TP and Poly-TPE whose monomers have more than two conjugated benzene rings, show superior photothermal conversion efficiencies of over $47 \%$. Also, the high thermal-/photo-stability ensure the repeated use of these CMPs for sustainable energy conversion. PolyTPE was demonstrated to act as a photothermal filler to remotely and spatially control the shape recovery of thermal-sensitive SMP materials under NIR irradiation at $808 \mathrm{~nm}$. Therefore, the excellent NIR photothermal performance of Poly-TPE and Poly-TP, in combination with their facile one-step synthetic preparation, makes them highly promising polymeric materials for photothermal use in practical applications such as medicine, robotics and intelligent systems.
Received 11 March 2020; accepted 20 May 2020; published online 11 August 2020

1 Das S, Heasman P, Ben T, et al. Porous organic materials: Strategic design and structure-function correlation. Chem Rev, 2017, 117: $1515-1563$

2 Liu F, Huang $\mathrm{K}, \mathrm{Wu} \mathrm{Q}$, et al. Solvent-free self-assembly to the synthesis of nitrogen-doped ordered mesoporous polymers for highly selective capture and conversion of $\mathrm{CO}_{2}$. Adv Mater, 2017, 29: 1700445

3 Luo Y, Li B, Wang W, et al. Hypercrosslinked aromatic heterocyclic microporous polymers: A new class of highly selective $\mathrm{CO}_{2}$ capturing materials. Adv Mater, 2012, 24: 5703-5707

4 Ma H, Wang Z, Zhao YH, et al. Microporous polymer based on hexaazatriphenylene-fused triptycene for $\mathrm{CO}_{2}$ capture and conversion. Sci China Mater, 2020, 63: 429-436

5 Dawson R, Cooper AI, Adams DJ. Nanoporous organic polymer networks. Prog Polym Sci, 2011, 37: 530-563

$6 \mathrm{Xu} \mathrm{Y}$, Jin $\mathrm{S}, \mathrm{Xu} \mathrm{H}$, et al. Conjugated microporous polymers: Design, synthesis and application. Chem Soc Rev, 2013, 42: 80128031

7 Li L, Cai K, Wang P, et al. Construction of sole benzene ring porous aromatic frameworks and their high adsorption properties. ACS Appl Mater Interfaces, 2015, 7: 201-208

$8 \mathrm{Xu} \mathrm{Y}$, Cui D, Zhang S, et al. Facile synthesis of conjugated microporous polymer-based porphyrin units for adsorption of $\mathrm{CO}_{2}$ and organic vapors. Polym Chem, 2019, 10: 819-822

9 Jiang JX, Su F, Trewin A, et al. Synthetic control of the pore dimension and surface area in conjugated microporous polymer and copolymer networks. J Am Chem Soc, 2008, 130: 7710-7720

10 Schmidt J, Werner M, Thomas A. Conjugated microporous polymer networks via Yamamoto polymerization. Macromolecules, 2009, 42: 4426-4429

$11 \mathrm{Xu} \mathrm{Y,} \mathrm{Chen} \mathrm{L,} \mathrm{Guo} \mathrm{Z,} \mathrm{et} \mathrm{al.} \mathrm{Light-emitting} \mathrm{conjugated} \mathrm{polymers}$ with microporous network architecture: Interweaving scaffold promotes electronic conjugation, facilitates exciton migration, and improves luminescence. J Am Chem Soc, 2011, 133: 17622-17625

12 Kou Y, Xu Y, Guo Z, et al. Supercapacitive energy storage and electric power supply using an aza-fused $\pi$-conjugated microporous framework. Angew Chem Int Ed, 2011, 50: 8753-8757

13 Tan J, Wan J, Guo J, et al. Self-sacrificial template-induced modulation of conjugated microporous polymer microcapsules and shape-dependent enhanced photothermal efficiency for ablation of cancer cells. Chem Commun, 2015, 51: 17394-17397

14 Wang X, Liu Q, Wu S, et al. Multilayer polypyrrole nanosheets with self-organized surface structures for flexible and efficient solar-thermal energy conversion. Adv Mater, 2019, 31: 1807716

15 Espín J, Garzón-Tovar L, Carné-Sánchez A, et al. Photothermal activation of metal-organic frameworks using a UV-Vis light source. ACS Appl Mater Interfaces, 2018, 10: 9555-9562

$16 \mathrm{Xu} \mathrm{W}, \mathrm{Hu} \mathrm{X}$, Zhuang $\mathrm{S}$, et al. Flexible and salt resistant Janus absorbers by electrospinning for stable and efficient solar desalination. Adv Energy Mater, 2018, 8: 1702884

17 Kim B, Shin H, Park T, et al. NIR-sensitive poly(3,4-ethylenedioxyselenophene) derivatives for transparent photo-thermoelectric converters. Adv Mater, 2013, 25: 5483-5489

18 Cheng L, Wang C, Feng L, et al. Functional nanomaterials for phototherapies of cancer. Chem Rev, 2014, 114: 10869-10939

19 Yang Z, Han X, Lee HK, et al. Shape-dependent thermo-plasmonic effect of nanoporous gold at the nanoscale for ultrasensitive heat- 
mediated remote actuation. Nanoscale, 2018, 10: 16005-16012

20 Ou C, Zhang Y, Pan D, et al. Zinc porphyrin-polydopamine coreshell nanostructures for enhanced photodynamic/photothermal cancer therapy. Mater Chem Front, 2019, 3: 1786-1792

21 Han B, Zhang YL, Chen QD, et al. Carbon-based photothermal actuators. Adv Funct Mater, 2018, 28: 1802235

22 Robinson JT, Tabakman SM, Liang Y, et al. Ultrasmall reduced graphene oxide with high near-infrared absorbance for photothermal therapy. J Am Chem Soc, 2011, 133: 6825-6831

23 Huang S, Ma P, Wei Y, et al. Controllable synthesis of hollow porous silica nanotubes/CuS nanoplatform for targeted chemophotothermal therapy. Sci China Mater, 2020, 63: 864-875

24 Guo LX, Liu MH, Sayed SM, et al. A calamitic mesogenic nearinfrared absorbing croconaine dye/liquid crystalline elastomer composite. Chem Sci, 2016, 7: 4400-4406

25 Li Z, Yang Y, Wang Z, et al. Polydopamine nanoparticles doped in liquid crystal elastomers for producing dynamic 3D structures. J Mater Chem A, 2017, 5: 6740-6746

$26 \mathrm{Ou} \mathrm{H}, \mathrm{Li}$ J, Chen C, et al. Organic/polymer photothermal nanoagents for photoacoustic imaging and photothermal therapy in vivo. Sci China Mater, 2019, 62: 1740-1758

27 Liu Y, Ai K, Liu J, et al. Dopamine-melanin colloidal nanospheres: An efficient near-infrared photothermal therapeutic agent for in vivo cancer therapy. Adv Mater, 2013, 25: 1353-1359

28 Xu L, Cheng L, Wang C, et al. Conjugated polymers for photothermal therapy of cancer. Polym Chem, 2014, 5: 1573-1580

29 He Y, Wang Y. Near-infrared photothermal conversion based on polymer materials. Acta Polym Sin, 2019, 50: 102-108

30 Zhang Y, Zhou S, Chong KC, et al. Near-infrared light-induced shape memory, self-healable and anti-bacterial elastomers prepared by incorporation of a diketopyrrolopyrrole-based conjugated polymer. Mater Chem Front, 2019, 3: 836-841

31 Yang $\mathrm{K}, \mathrm{Xu} \mathrm{H}$, Cheng $\mathrm{L}$, et al. In vitro and in vivo near-infrared photothermal therapy of cancer using polypyrrole organic nanoparticles. Adv Mater, 2012, 24: 5586-5592

32 Yang J, Choi J, Bang D, et al. Convertible organic nanoparticles for near-infrared photothermal ablation of cancer cells. Angew Chem Int Ed, 2011, 50: 441-444

33 Zha Z, Yue X, Ren Q, et al. Uniform polypyrrole nanoparticles with high photothermal conversion efficiency for photothermal ablation of cancer cells. Adv Mater, 2013, 25: 777-782

34 Shi Y, Liu S, Liu Y, et al. Facile fabrication of nanoscale porphyrinic covalent organic polymers for combined photodynamic and photothermal cancer therapy. ACS Appl Mater Interfaces, 2019, 11: 12321-12326

35 Cao Y, Dou JH, Zhao N, et al. Highly efficient NIR-II photothermal conversion based on an organic conjugated polymer. Chem Mater, 2016, 29: 718-725

36 Chen P, Ma Y, Zheng Z, et al. Facile syntheses of conjugated polymers for photothermal tumour therapy. Nat Commun, 2019, 10: 1192

37 Msayib KJ, McKeown NB. Inexpensive polyphenylene network polymers with enhanced microporosity. J Mater Chem A, 2016, 4: 10110-10113

38 Wang S, Zhang C, Shu Y, et al. Layered microporous polymers by solvent knitting method. Sci Adv, 2017, 3: e1602610

39 Hou S, Tan B. Naphthyl substitution-induced fine tuning of porosity and gas uptake capacity in microporous hyper-cross-linked amine polymers. Macromolecules, 2018, 51: 2923-2931

40 Hou S, Razzaque S, Tan B. Effects of synthesis methodology on microporous organic hyper-cross-linked polymers with respect to structural porosity, gas uptake performance and fluorescence properties. Polym Chem, 2019, 10: 1299-1311

41 Jeong HK, Jin MH, So KP, et al. Tailoring the characteristics of graphite oxides by different oxidation times. J Phys D-Appl Phys, 2009, 42: 065418

42 Teweldebrhan D, Balandin AA. Modification of graphene properties due to electron-beam irradiation. Appl Phys Lett, 2009, 94: 013101

43 Ferrari AC, Robertson J. Interpretation of Raman spectra of disordered and amorphous carbon. Phys Rev B, 2000, 61: 1409514107

44 Lü B, Chen Y, Li P, et al. Stable radical anions generated from a porous perylenediimide metal-organic framework for boosting nearinfrared photothermal conversion. Nat Commun, 2019, 10: 767

45 Wang J, Zhao J, Li Y, et al. Enhanced light absorption in porous particles for ultra-NIR-sensitive biomaterials. ACS Macro Lett, 2015, 4: 392-397

46 Xie H, Shao J, Ma Y, et al. Biodegradable near-infrared-photoresponsive shape memory implants based on black phosphorus nanofillers. Biomaterials, 2018, 164: 11-21

47 Li Z, Zhang X, Wang S, et al. Polydopamine coated shape memory polymer: Enabling light triggered shape recovery, light controlled shape reprogramming and surface functionalization. Chem Sci, 2016, 7: 4741-4747

48 Liu W, Guo LX, Lin BP, et al. Near-infrared responsive liquid crystalline elastomers containing photothermal conjugated polymers. Macromolecules, 2016, 49: 4023-4030

49 Feng Z, Hu J, Zuo H, et al. Photothermal-induced self-healable and reconfigurable shape memory bio-based elastomer with recyclable ability. ACS Appl Mater Interfaces, 2019, 11: 1469-1479

Acknowledgements This work was supported by the National Natural Science Foundation of China (51503231 and 21374136), Guangdong Innovative and Entrepreneurial Research Team Program (2013S086), and the Fundamental Research Funds for the Central Universities (17lgjc03 and 18lgpy04).

Author contributions Huang $\mathrm{H}$ and Liang $\mathrm{G}$ designed the project. $\mathrm{Wu}$ $\mathrm{J}, \mathrm{Wu} \mathrm{Y}$ and $\mathrm{He} \mathrm{Z}$ performed the experiments. Huang $\mathrm{H}$ and $\mathrm{Wu} \mathrm{J}$ cowrote the paper. All authors contributed to the general discussion.

Conflict of interest The authors declare that they have no conflict of interest.

Supplementary information Supporting data are available in the online version of the paper, including TGA, nitrogen sorption isotherm and pore size distribution curves, and NIR emission spectra of CMPs, calculation process of photothermal conversion efficiency, and DSC, TGA, DMA and strain-stress curves of SMPU/CMP composite films. 


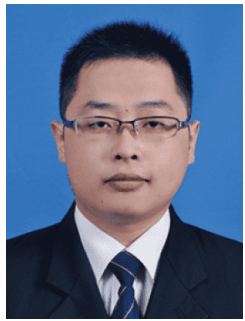

Jialong Wu got his BSc and MSc degrees from the School of Chemistry and Chemical Engineering, Sun Yat-sen University. He is a $\mathrm{PhD}$ candidate at the School of Materials Science and Engineering, Sun Yat-sen University. His research interests focus on the application of porous polymers in environment and energy conversion.

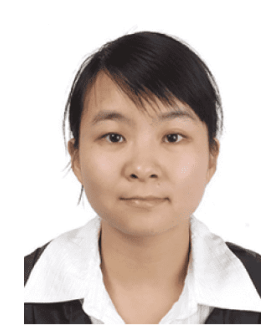

Huahua Huang is an associate professor at the School of Materials Science and Engineering, Sun Yat-sen University. She got her PhD degree from the Institute of Chemistry, Chinese Academy of Sciences in 2010. Her research interest mainly focuses on the syntheses and applications of functional polymers and shape memory polymers.

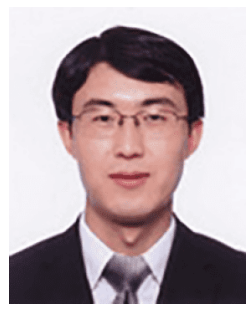

Guodong Liang is a professor at the School of Materials Science and Engineering, Sun Yat-sen University, China. He received his $\mathrm{PhD}$ degree from Zhejiang University in 2007. His research interest mainly focuses on constructing functional materials and exploiting their applications.

\section{共轭多孔聚合物应用于近红外光热转换材料}

吴嘉龙 ${ }^{1}$, 吴咏卫 ${ }^{1}$, 贺泽芒 ${ }^{2}$, 李字华 ${ }^{1}$, 黄华华 ${ }^{1 *}$, 陈永明 ${ }^{1}$, 梁国栋

摘要 近红外光热转换材料在光热治疗、光驱动智能器件等医学 和能源领域受到广泛重视. 本文以商业化芳香小分子为单体, 通过 一步简单的交联聚合方法制得了四种共轭多孔聚合物, 并首次系 统研究了它们的光热转换性能. 结果表明, 它们均具有灵敏的近红 外光热响应性, 且材料的光热转换效率与单体结构中共轭苯环数 有很大关系, 其中两种聚合物的光热转换效率可高达 $47 \%$ 以上. 同 时, 该类共轭多孔聚合物可作为光热转换填料, 将其少量填充于热 敏型形状记忆材料基体中, 可实现远程、快速、定点调控材料形 状的回复, 且其对基材的热性质和力学性能影响很小. 研究表明, 由于其合成简单、原料易得、光热转换效率高, 该共轭多孔聚合 物是一类很有应用前景的光热转换材料. 